\title{
Effects of Rotating Shaft Misalignment on Bearing Life and Lubricant Failure
}

\author{
Anthony Simons ${ }^{1, *}$, Henry Otoo $^{2}$, Solomon Nunoo ${ }^{3}$, Ernest Ababio ${ }^{1}$, Cyrus Addy $^{1}$ \\ ${ }^{1}$ Department of Mechanical Engineering, Faculty of Engineering, University of Mines and Technology, Tarkwa, Ghana \\ ${ }^{2}$ Department of Mathematical Sciences, Faculty of Engineering, University of Mines and Technology, Tarkwa, Ghana \\ ${ }^{3}$ Department of Electrical and Electronics Engineering, Faculty of Engineering, University of Mines and Technology, Tarkwa, Ghana
}

Email address:

asimons@umat.edu.gh (A. Simons), hotoo@umat.edu.gh (H. Otoo), snunoo@umat.edu.gh (S. Nunoo), ababiogh@yahoo.com (E. Ababio), caddy@umat.edu.gh (C.Addy)

${ }^{*}$ Corresponding author

\section{To cite this article:}

Anthony Simons, Henry Otoo, Solomon Nunoo, Ernest Ababio, Cyrus Addy. Effects of Rotating Shaft Misalignment on Bearing Life and Lubricant Failure. American Journal of Mechanical and Materials Engineering. Vol. 4, No. 3, 2017, pp. 48-53. doi: 10.11648/j.ajmme.20200403.12

Received: April 22, 2020; Accepted: June 30, 2020; Published: August 18, 2020

\begin{abstract}
This study looks at plant and machinery at West African Mills Company Limited (WAMCO), with the view to identify sections within the factories with high cost of maintenance and provide a solution to reduce operating costs. Records of breakdowns at various sections of the plant were analysed and the first stage milling section at WAMCO II was found to have the highest cost of maintenance. On average, the breakdown of each of the three SCS4 grinding mills is about 14 times in a year. Furthermore, 27 bearings and 1.625 buckets of grease are used on the grinding mills alone costing an average of $€ 10,000.00$ annually on their maintenance. Some experiments were performed to ascertain how the rotating shaft misalignment occurs and the consequent change in parameters such as temperature, viscosity, power, and vibration. Bearing temperature readings at various misaligned shaft positions gave some indication of the criticality and likelihood of machine breakdowns. It was observed from the correlation analysis that there exist a strong positive relationship between the number of bearings, bucket of grease and man-hours used during breakdown and repairs. It was recommended that modern devices for monitoring be acquired and proper condition monitoring of the plant made to minimize the plant breakdowns and save money. Also, proper selection of bearing type for the mills should be looked at.
\end{abstract}

Keywords: Rotating Shaft, Maintenance, Misalignment, Bearing, Lubricant

\section{Introduction}

With the current requirements of lean production, organizations are compelled to reduce cost, manage operations effectively, control budget properly, and minimize plant/equipment downtime [1]. One momentous operation is the periodic re-alignment of rotating coupled shafts of machines. This helps to reduce the maintenance and operating costs of the plant [2]. Indeed, the Maintenance and Reliability Centre of the University of Tennessee, Knoxville, indicates that a $5 \mathrm{mil}(0.005$ inches or $0.127 \mathrm{~mm})$ offset misalignment can reduce expected bearing life by as much as $50 \%$ in some cases [3].

The management of West African Mills Company Limited (WAMCO), Takoradi observed a decrease in the efficiency of their machines and the initial checks pointed to shaft misalignment on the SCS4 grinding mills. Shaft misalignment results in rotor imbalance, vibration, and wear [4]. Also, high running temperatures and bearing collapse have been noticed on the Plummer block.

Each of the three SCS4 grinding mills experiences, on the average, 14 breakdown each year. These breakdowns have an adverse effect on the company in terms of the cost of maintenance and repair, and hamper daily production levels. It is therefore imperative that we carry out studies to establish the extent of effect of rotating coupled shaft misalignment on bearing life and lubricants in plant and machinery at WAMCO and also establish the relationship between the number of bearings, buckets of grease and man-hours used as a result of the misalignment. 


\section{Resources and Methods Used}

\subsection{Plant Data}

Records available at the plant were History of Plant Maintenance/Repairs (2006-2013) and average Expenditure on Maintenance/Repairs (2006-2013) for Buhler SCS4 no. 1 Mill and 1st Stage Milling. These data are depicted in Tables 1, 2 and 3 , respectively.

Table 1. Bearing and grease usage records for Buhler SCS4 no. 1 mill (2006-2013).

\begin{tabular}{lll}
\hline Year & No. of Bearings Used & No. of Buckets of Grease used \\
\hline 2006 & 24 & 1.50 \\
2007 & 24 & 1.50 \\
2008 & 26 & 1.60 \\
2009 & 28 & 1.70 \\
2010 & 27 & 1.65 \\
2011 & 29 & 1.80 \\
2012 & 25 & 1.55 \\
2013 & 28 & 1.70 \\
\hline
\end{tabular}

Table 2. Average cost of maintenance first stage milling (2006-2013).

\begin{tabular}{lc}
\hline Description & Cost (€) \\
\hline Total cost of maintenance and repair (Processing & $65,000.00$ \\
plant/equipment) & $10,000.00$ \\
Cost of breakdown repair (SCS4 Grinding mill) & $7,950.00$ \\
Cost of repairs due to shaft misalignment on grinding mills & $2,050.00$ \\
\hline Cost of Maintenance/repairs due to other factors & \\
\hline
\end{tabular}

Table 3. Average man-hour cost of maintenance for Buhler SCS4 no. 1 mill (2006-2013).

\begin{tabular}{ll}
\hline Year & Man-Hour $(\boldsymbol{\epsilon})$ \\
\hline 2006 & 2416.00 \\
2007 & 2416.00 \\
2008 & 2718.00 \\
2009 & 2818.67 \\
2010 & 2718.00 \\
2011 & 2919.30 \\
2012 & 2516.67 \\
2013 & 2818.67 \\
\hline
\end{tabular}

It was observed from Table 1 that the average annual usage of bearings and buckets of grease was 27 and 1.625, respectively. Also, from Table 2, shaft misalignment constituted $79.5 \%$ of the cost of breakdown repair of the grinding mills. The average cost of buckets of grease and bearing was $€ 318.00$ and $€ 182.00$, respectively.

\subsection{Experimental Set-Up}

SCS4 grinding mill was selected randomly out of the three installed mills and was observed in running so that the total plant output would not be disrupted. These mills grind cocoa nibs to coarse cocoa liquor using a grinding rotor (drum) with attached beater blades and casing grinding grate. The rotor is driven by an induction motor coupled to a shaft and mounted on two support block bearings installed on a metal table. The plant specification is as indicated in Table 4.

As shown in Figure 1, Cocoa nibs in the Hooper are fed via screw conveyor to the feeder into the rotor assembly, which is made up of a rotor, beater blades, and nib crusher grate. The cocoa nibs are ground into coarse cocoa liquor and flow out through a spout and liquor trough to the next stage grinding.

The control panel supplies energy (Electric power) to an induction motor to turn the rotor assembly through a coupling-shaft arrangement mounted on support bearings [5].

Table 4. Plant specifications.

\begin{tabular}{ll}
\hline Item & Specification \\
\hline Plant capacity & 2 tonnes of cocoa beans per hour \\
Rotating shaft diameter & $25 \mathrm{~mm}$ \\
Rotating shaft speed & $2900 \mathrm{rpm}$ \\
Drive motor power & $45 \mathrm{~kW}$ \\
Bearing & 22314 \\
Split Plummer block & $516-613$ \\
Grease & ISO VG 100 (Mobilith SHC 100) \\
Grease viscosity at $40^{\circ} \mathrm{C}$ & $100 \mathrm{cSt}\left(\mathrm{mm}^{2} / \mathrm{sec}\right)$ \\
$\begin{array}{l}\text { Grease maximum operating } \\
\text { temperature }\end{array}$ & $150^{\circ} \mathrm{C}$ \\
$\begin{array}{l}\text { Coupling Type } \\
\text { Number of hours plant is in normal } \\
\text { operation }\end{array}$ & Flexible Jaw Coupling \\
Number of hours plant is in & 24 hour per day \\
operation during the experiment & 24 hours @ 10 days \\
\hline
\end{tabular}

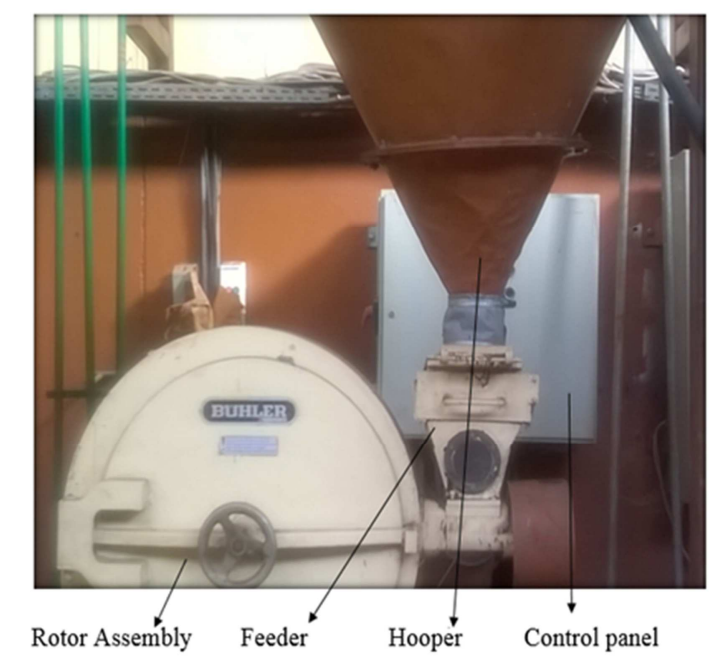

Figure 1. SCS4 grinding mill.

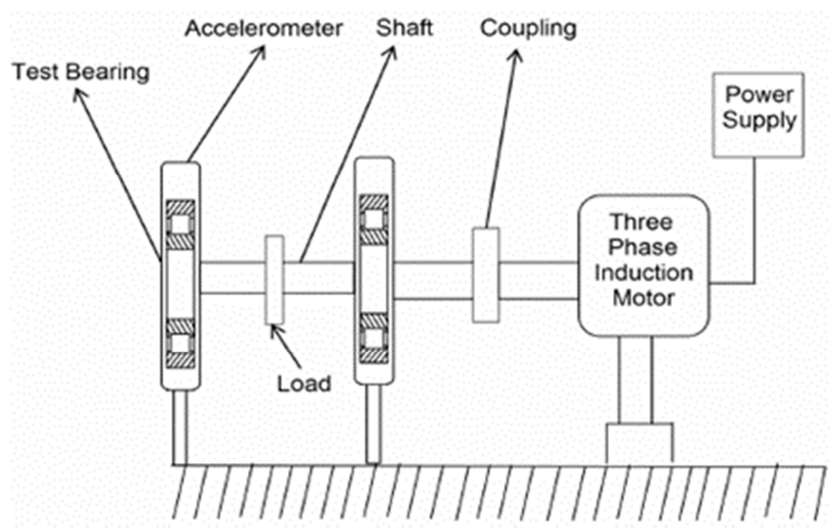

Figure 2. Schematic diagram of the rotor-bearing system.

Figure 2 [6] is a schematic diagram showing a plant installation arrangement, which includes an induction motor 
coupled to a rotating shaft mounted on two support block bearings.

\subsection{Data Acquisition}

All changes in normal alignment positions were made in the vertical plane with the motor operating under maximum speed, full load, and half load conditions. The system was run for 24 hours so that constant operating temperatures were attained [7]. Misalignment condition was varied at $0.25 \mathrm{~mm}$ vertical offset by varying the shim packs at key points and at each misaligned position, temperature, viscosity, vibration, and motor current readings were taken ten times and averages computed. At high temperatures where bearings collapsed, the damaged bearings were changed, and the procedure repeated. The experiment was done at 24 hours intervals with roller bearings for 10 days on the grinding mill [8]. The steps taken in the experiments are in consonance with that of Vogel (2016) [9].

The position sensor and laser diode were mounted with brackets on the shaft at opposite sides of coupling as shown in Figure 3 with a handheld monitor. The shafts were rotated, and shaft positions and alignment readings automatically calculated and shown on the monitor.

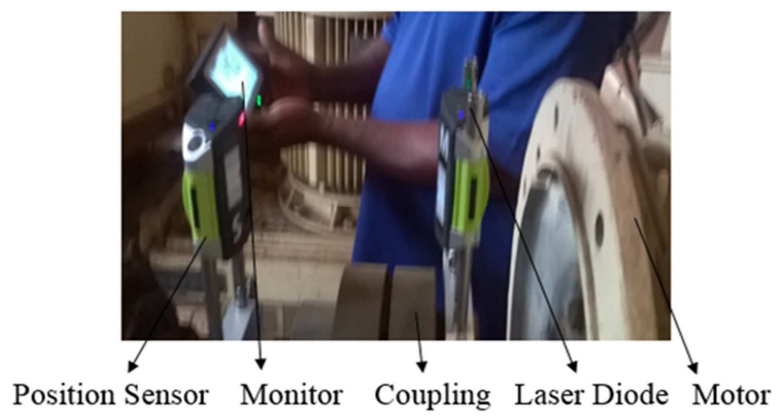

Figure 3. Laser alignment recording process and checks.

\subsection{Correlation Analysis}

Correlation analysis measures the relationship between the two quantitative variables which are continuous in nature [10]. The association between the two variables are monotonic. With correlated data involving two variables, change in the magnitude of one variable is always associated with the change in magnitude of the other variable. This change can be in the same or opposite directions. In other words high values of one variable tend to be associated with higher (positive correlation) or lower (negative correlation).

\subsubsection{Pearson's Product-Moment Correlation Coefficient}

The Pearson product-moment correlation coefficient (or Pearson correlation coefficient) is a measure of the strength of a linear association between two variables and is denoted by $r$ [11].

The Pearson correlation coefficient, $r$, can take a range of values from +1 to -1 . A value of 0 indicates that there is no association between the two variables. A value greater than 0 indicates a positive association; that is, as the value of one variable increases, so does the value of the other variable. A value less than 0 indicates a negative association; that is, as the value of one variable increases, the value of the other variable decreases [12]. The stronger the association of the two variables, the closer the Pearson correlation coefficient, $r$, will be to either +1 or -1 depending on whether the relationship is positive or negative, respectively. Achieving a value of +1 or -1 means that all your data points are included on the line of best fit and that there are no data points that show any variation away from this line.

Mathematically, given the ordered pair data $\left\{\left(\mathrm{x}_{1}, \mathrm{y}_{1}\right), \ldots,\left(\mathrm{x}_{\mathrm{n}}, \mathrm{y}_{\mathrm{n}}\right)\right\}$, the Pearson's correlation coefficient for a given sample is given by:

$$
r_{x y}=\frac{\left(n \sum x_{i} y_{i}-\sum x_{i} \sum y_{i}\right)}{\left(\sqrt{n \sum x_{i}^{2}-\left(x_{i}\right)^{2}} \sqrt{n \sum y_{i}^{2}-\left(y_{i}\right)^{2}}\right)}
$$

Where $n$ is the sample size and $x_{i}, y_{i}$ are the individual sample points indexed with $i$.

When the value of $r$ is near 0 , the linear relationship is weak or nonexistent. Since the value of $r$ is computed from data obtained from samples, there are two possibilities when $r$ is not equal to zero: either the value of $r$ is high enough to conclude that there is a significant linear relationship between the variables, or the value of $r$ is due to chance.

\subsubsection{Significance Level and P-Value}

The significance level is a measure of the strength of the evidence that must be present on a sample before the null hypothesis can be rejected and concluded that the effect is statistically significant. The significance level is the probability of rejecting the null hypothesis when it is true. Lower significance level indicate that a stronger evidence is required before you reject the null hypothesis. Normally in drawing inferences in hypothesis testing, the significance level and p-value of the sample are compared. The P-value is the probability of obtaining results as extreme as the observed results of a statistical hypothesis test, assuming that the null hypothesis is correct. If the p-value is less than the significance level, the null hypothesis is rejected and concluded that the effect is statistically significant. In other words the evidence in your sample is strong enough to be able to reject the null hypothesis at the population level.

\section{Results and Discussions}

Data collected from the misalignment experiment were analyzed to determine the correlations in temperature, current, vibration, and viscosity with respect to each misaligned position. Averages for various instrumental readings were tabulated and graphs plotted for trends and comments.

The results from the experiment show that for each misaligned position there were induced bearing loads that increased vibration, friction, abrasions, fatigue, and heat with high bearing operating temperatures, which subsequently, lowered grease viscosities. The following subsections provide specifics of the analysis conducted. 


\subsection{Effects of Misalignment on Temperature}

It could be seen from Figure 4 that when the mill is run without cooling by air, the effect of misalignment offset of the mill shaft on bearing temperature for the operating loads of 2 ton $/ \mathrm{hr}$ and $1 \mathrm{ton} / \mathrm{hr}$ is the same for misalignment offset of 1.25 $\mathrm{mm}$ to $3.00 \mathrm{~mm}$. However, the bearing temperatures are slightly lower for half load (1 ton/hr) from misalignment offsets of $0 \mathrm{~mm}$ to $1.23 \mathrm{~mm}$. When compressed air was used to dissipate heat from the setup, it was observed that there was an average decrease in temperature from misalignment offset of 0 $\mathrm{mm}$ to $2.25 \mathrm{~mm}$, after which there was no difference under this condition and the former.

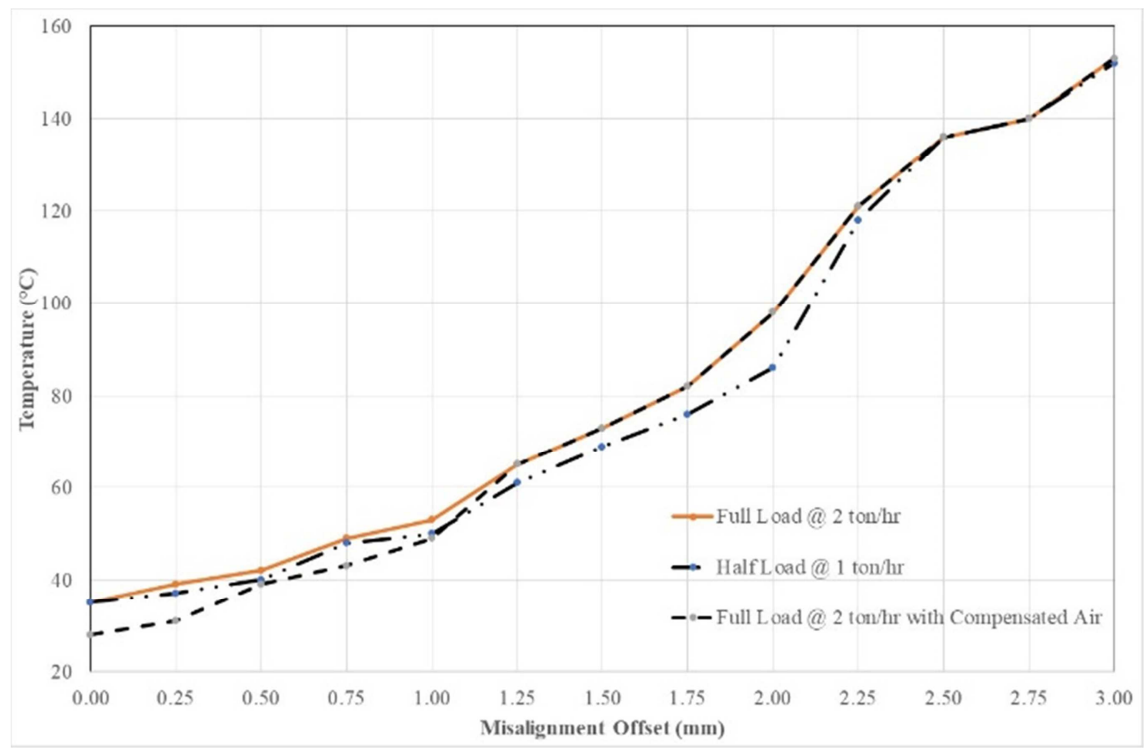

Figure 4. Effects of misalignment on temperature at both full load and half load.

Also, we observed that the temperature increase resulting from the shaft misalignment led to reduction in grease viscosity as shown in Figure 5. At misalignment offset of 0 $\mathrm{mm}$, the bearing temperature was around $35^{\circ} \mathrm{C}$ and the grease viscosity was $2000 \mathrm{~mm}^{2} / \mathrm{s}$. When the misalignment offset was increase by $0.25 \mathrm{~mm}$, the grease viscosity dropped by $900 \%$ and the temperature increased. Increase in misalignment increases frictional resistance to motion. This in effect causes the operating temperature of the bearing to rise, consequently, causing a huge drop in viscosity. This meant that the lubrication regime of the system would move from hydrodynamic to mixed or thin -film regime and therefore, increase the metal to metal contact between the bearing and its housing.

Considering the decrease in viscosity resulting from the increased temperature, and the subsequent low load carrying capacity of the grease, any additional increase in the misalignment offset, as seen in Figure 5, would exponentially increase the bearing temperature.

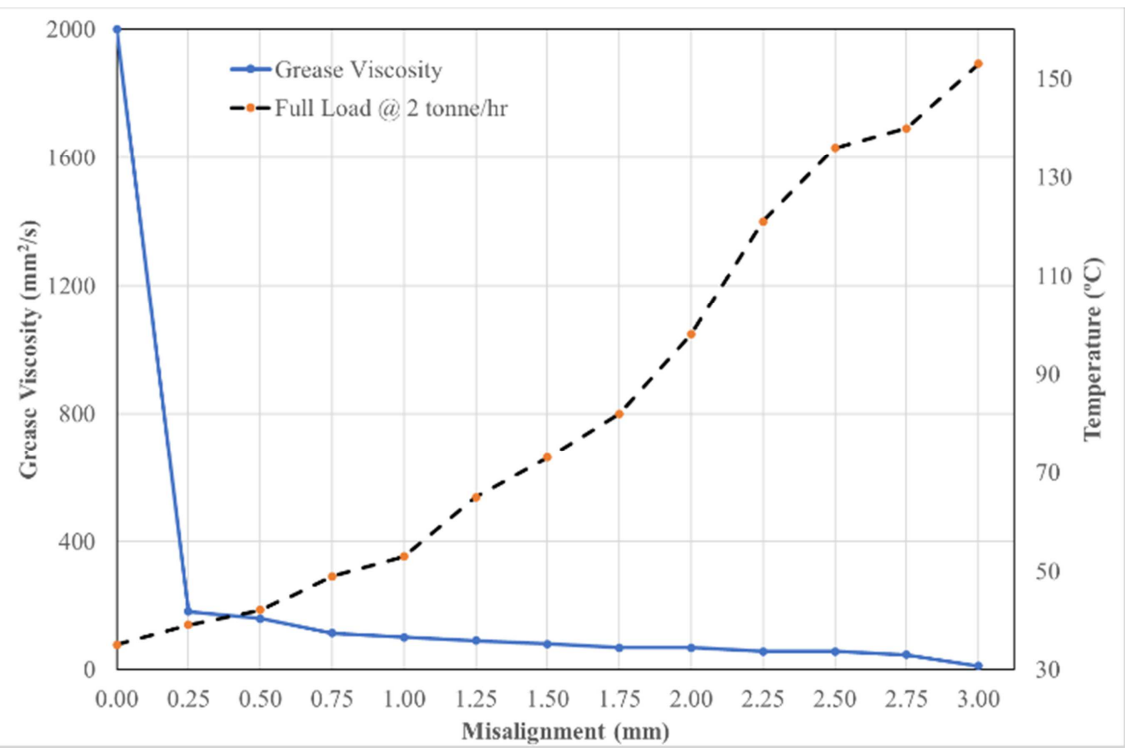

Figure 5. Effects of temperature on grease viscosity. 


\subsection{Effects of Grease Viscosity on Bearing Life}

As seen from Figure 6, increase in misalignment offset from $0 \mathrm{~mm}$ to $0.25 \mathrm{~mm}$ decreases the viscosity of the grease from $2000 \mathrm{~mm}^{2} / \mathrm{s}$ to about $200 \mathrm{~mm}^{2} / \mathrm{s}$ whereas the bearing life decreases from 7500 hours to 7000 hours, which is a drop of $6.6 \%$. At this stage, the viscosity of the grease has decreased by $900 \%$, as discussed in Section 3.1. An increase in misalignment offset by $0.25 \mathrm{~mm}$, i.e. from $0.25 \mathrm{~mm}$ to 0.50 $\mathrm{mm}$ ) decreases the bearing life linearly by $46.66 \%$. Further, increase in misalignment offset from $0.50 \mathrm{~mm}$ to $2.00 \mathrm{~mm}$ shows exponential decrease in bearing life from 4000 hours to 110 hours.

Misalignment is an excessive steady and dynamic loading which causes disruption of the oil film at the edge of the bearing [14]. This means that as misalignment offset increases, there would be inadequate or insufficient lubricant in the system. Again, because the viscosity of the grease has decreased, its film thickness becomes negligible and the lubrication regime turns to boundary where there is metal to metal contact and excessive heat is generated. The combined effect is that any further increase in misalignment offset from $2.00 \mathrm{~mm}$ onwards results in bearing collapse (i.e. melting).

\subsection{Effects of Vibrations on Power Consumption}

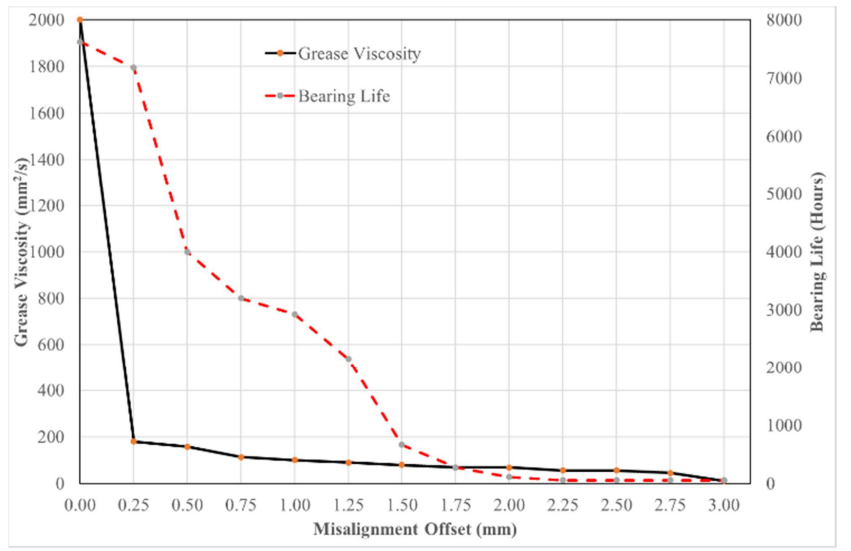

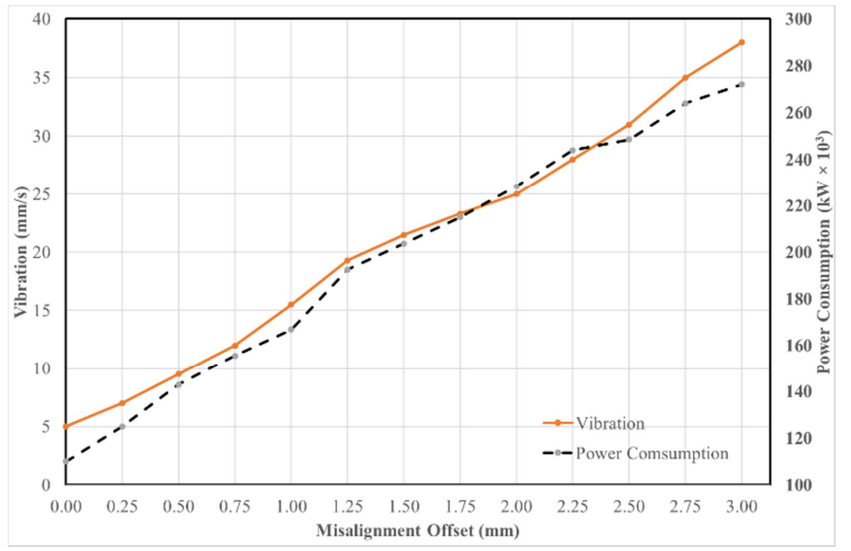

Figure 7. Effects of vibrations on power consumption.

Vibrations can result when machine shafts are out of line, resulting in the damaging of roller bearing. According to [15], the effects of vibration can be severe; accelerate the rate of wear, thereby reducing bearing life, and damage equipment. It can cause machinery to consume excessive power and may damage product quality. If unchecked, it may knock equipment out of service and halt plant operation.

From Figure 7, as misalignment offset increases, power consumption also increases proportionally to the rise in vibration levels, such that, for every rise of $2.75 \mathrm{~mm} / \mathrm{s}$ in vibration, there is a corresponding increase of $13.33 \times 10^{3} \mathrm{~kW}$ of power consumption.

\subsection{Determination of the Pearson Correlation Coefficient}

Breakdowns and repairs of machines in any processing plant adversely affect the finances of a company due to cost of materials and labour involved. The study therefore examines the relationship between the number of bearings, buckets of grease and the man-hours used during the breakdowns and repairs due to the rotating shaft misalignment. To investigate whether there exist such relationship, the Pearson correlation coefficient in equation (1) is used using the SPSS software.

Figure 6. Effects of grease viscosity on bearing life.

Table 5. Correlation Matrix

\begin{tabular}{lllll}
\hline & & No. of Bearings & No. of Buckets of Grease & Man-Hours \\
\hline No. of Bearings & Pearson Correlation & 1 & $0.990^{* *}$ & $0.983^{* *}$ \\
& Sig (2-tailed) & & .000 & .000 \\
No. of buckets Grease & N & 8 & 8 & 8 \\
& Pearson Correlation & $0.990^{* *}$ & 1 & $0.971^{* *}$ \\
& Sig (2-tailed) & .000 & 8 & .000 \\
Man-Hours & N & 8 & $0.971^{* *}$ & 8 \\
& Pearson Correlation & $0.983^{* *}$ & .000 & 1 \\
& Sig (2-tailed) & .000 & 8 & 8 \\
\hline
\end{tabular}

** Correlation is significant at the 0.01 level (2-tailed).

There exit a strong positive relationship between the number of bearings and buckets of grease used with a correlation coefficient of 0.99 as indicated in table 5. This relationship is highly significant at $1 \%$ with a p-value of 0.00 which implies that an increase in the number of bearings used during the breakdown and repairs will result in an increase in 
the number of buckets of grease used. Also, as seen in table 5, the correlation coefficient between a bucket of grease and man hours used is 0.971 which is also highly significant at $1 \%$ with a p-value of 0.00 . This indicates the existence of a strong positive relationship between the number of buckets of grease and man-hours. Therefore, any increment in the number of buckets of grease used will lead to a corresponding increment in the man-hours used during the breakdown and repairs. Furthermore, from table 5, a correlation coefficient of 0.983 which is significant at $1 \%$ with a p-value of 0.00 indicates a strong positive relationship between the number of bearings and man hours used during the breakdown and repair.

Therefore, strong positive relationship between these three quantities (buckets of grease, bearings and man-hours) implies that an increase in the cost of one of these quantities will result in an increase in the cost of the other two. Thus, the existence of the rotating shaft misalignment on the SCS4 grinding mills will increase the maintenance and production cost if the frequent yearly breakdowns are not properly checked.

\section{Conclusions}

Experiments have been carried on shaft misalignment offset and its effects on bearing temperature, lubricant viscosity, power consumption and vibration. It could be concluded that when the mill was ran without cooling by air, the effect of misalignment offset of the mill shaft on bearing temperature for the operating loads of $2 \mathrm{ton} / \mathrm{hr}$ and $1 \mathrm{ton} / \mathrm{hr}$ was the same for misalignment offset of $1.25 \mathrm{~mm}$ to $3.00 \mathrm{~mm}$. However, the bearing temperatures were slightly lower for half load (1 ton/hr) from misalignment offsets of $0 \mathrm{~mm}$ to $1.23 \mathrm{~mm}$. When compressed air was used to dissipate heat from the setup, it was observed that there was an average decrease in temperature from misalignment offset of $0 \mathrm{~mm}$ to $2.25 \mathrm{~mm}$ for full load of 2 ton $/ \mathrm{hr}$.

At misalignment offset of $0 \mathrm{~mm}$, the bearing temperature was around $35^{\circ} \mathrm{C}$ and the grease viscosity was $2000 \mathrm{~mm}^{2} / \mathrm{s}$. When the misalignment offset was increase by $0.25 \mathrm{~mm}$, the grease viscosity dropped by $900 \%$ and the temperature increased to $39^{\circ} \mathrm{C}$ whereas the bearing life decreases from 7500 hours to 7000 hours, which is a drop of $6.6 \%$.

Again, as misalignment offset increases, power consumption also increases proportionally to the rise in vibration levels, such that, for every rise of $2.75 \mathrm{~mm} / \mathrm{s}$ in vibration, there was a corresponding increase of $13.33 \times 10^{3}$ $\mathrm{kW}$ of power consumption.

It was observed from the correlation analysis that there exist a strong positive relationship between the number of bearing, buckets of grease and man-hours used during breakdown and repairs and as such an increase in number of bearings used with results in an increase in the number of buckets of grease and man-hours.

It was recommended that modern devices for monitoring be acquired and proper condition monitoring of the plant made to minimize the plant breakdowns and save money. Also, proper selection of bearing type for the mills should be looked at.

\section{References}

[1] Vincze, P. Management of Continual Improvement for facilities and activities; A structured Approach. 2006: IAEA, pp. 78.

[2] Remack, K. Lovejoy, I and Downers, G. Keeping an Eye on Misalignment.

http://www.plantengineering.com/keep-an-eye-on -misalignment. (Accessed: March 21, 2019).

[3] Efficient Plant. Study Shows Shaft Misalignment Reduces Bearing Life. www.efficientplantmag.com/1999/04/studyshows-shaft-misalignment-reduces-bearing-life/(1999, Accessed March : 22, 2019).

[4] Verna A. K, Sarangi S and Kolekar M. Experimental Investigation of Misalignment Effects on Rotor Shaft Vibration and Stator Current Signature. J. Fail. Anal. Preven 2014; 14: $125-138$.

[5] Wankhede, A. Construction of a Phase Three Induction Motor on a Ship, http://www.marineinsight.com,(Accessed: March 30, 2019).

[6] Vakharia V, Gupta V. K and Kankar P. K, Ball Bearing Fault Diagnosis Using Supervised and Unsupervised Machine Learning Methods. Int. J Acou. Vib. 2015; 20: 244-250.

[7] Gamazo-Real, C. J, Vazquez-Sanchez, E and Gomez-Gil, J. Position and Speed Control of Brushless DC Motors Using Sensorless Techniques and Application Trends. Sensors 2010; 10 (7), 6901-6947.

[8] Piotrowski J, Shaft Alignment Handbook, 3rd Ed. Florida: CRC Press, 2006, pp. 862.

[9] Vogel B, Achieving proper alignment by detecting and correcting soft foot, http://www.easa.com, (2016, Accessed: March 30, 2019).

[10] Zou, K. H., Tuncali, K. and Silverman, S. G., 2003. Correlation and simple linear regression. Radiology, 227 (3), pp. 617-628.

[11] Puth, M. T., Neuhäuser, M. and Ruxton, G. D., 2014. Effective use of Pearson's product-moment correlation coefficient. Animal behaviour, 93, pp. 183-189.

[12] Taylor, R., 1990. Interpretation of the correlation coefficient: a basic review. Journal of diagnostic medical sonography, 6 (1), pp. 35-39.

[13] Royall, R. M., 1986. The effect of sample size on the meaning of significance tests. The American Statistician, 40 (4), pp. 313-315.

[14] Waukesha Bearings (2019), Rotor Dynamic Analysis. http://www.wuakbearing.com (Accessed: April 5, 2019).

[15] Saidur R. A review on electrical motors energy use and energy savings. Renewable and Sustainable Energy Reviews. 2010 Apr 1; 14 (3): 877-98.

[16] Wang, J. Management Science, Logistics and Operations Research, Buisness Science Reference, 2014, pp. 34.

[17] Shamir Ron. The Efficiency of the Simplex Method, Mgt Sci, 1987; 33 (3), 301-335. 